\title{
MÁS ALLÁ DEL TABÚ: PRENSA, MUJER Y SUICIDIO DURANTE LA RESTAURACIÓN
}

\author{
Víctor J. Ortega Muñoz* \\ Universidad de Málaga
}

\begin{abstract}
RESUMEN
Los avances en la ciencia histórica durante los últimos decenios han traído consigo aportaciones tan relevantes y necesarias como la aplicación de la perspectiva de género dentro de un amplio rango de investigaciones. El recuperar la voz de la mitad de la humanidad es un ejercicio de compromiso con la historia y con la búsqueda de una historia realmente universal.

En esta línea se inserta nuestro trabajo que, desde la base de la Historia de la Prensa y la Historia Social, pretende romper el tabú que se establece entre mujer y suicidio durante la Restauración española. El análisis del discurso conformado por la publicación de informaciones de sucesos protagonizados por mujeres que han optado por el recurso del suicidio se dirige a conocer mejor a dichas mujeres, sus características, motivaciones, contexto social y económico descubriendo las relaciones tanto de poder como morales vigentes durante el periodo estudiado.
\end{abstract}

PALABRAS CLAVE: suicidio, mujer, historia de género, sucesos, historia social

Enviado: 3/10/2019

Aceptado: 5/05/202

\footnotetext{
*vjortega@uma.es
} 


\title{
BEYOND THE TABU: PRESS, WOMAN AND SUICIDE DURING THE RESTORATION
}

\author{
Víctor J. Ortega Muñoz* \\ Universidad de Málaga
}

\begin{abstract}
Advances in historical science during the last decades have brought contributions as relevant and necessary as the application of the gender perspective within a wide range of research. Recovering the voice of half of humanity is an exercise in commitment to history and the search for a truly universal history.

In this line our paper is inserted, which from the base of the History of the Press and Social History, intends to break the taboo that is established between women and suicide during the Spanish Restoration. The analysis of the discourse formed by the publication of information on events starring women who have opted for the use of suicide is aimed at getting to know these women better, their characteristics, motivations, social and economic context, discovering the power and moral relationships in force during the period studied.
\end{abstract}

KEYWORDS: suicide, woman, gender history, events, social history

Enviado: 3/10/2019

Aceptado: 5/05/2020

*vjortega@uma.es 


\section{INTRODUCCIÓN: PRENSA, HISTORIA, GÉNERO Y SUCESOS}

El conjunto del trabajo del historiador engloba diversas cuestiones que influyen en el objetivo último del mismo: el acercamiento veraz a los hechos del pasado, no sólo con un fin meramente descriptivo, sino, ahondando también en el análisis y comprensión de los impulsos que los han suscitado. Es evidente que las fuentes, primarias o secundarias, directas o indirectas, constituyen la materia prima que determina en gran medida el resultado, en virtud de su profusión y fiabilidad, desde aproximaciones superficiales hasta trabajos de gran complejidad. En ocasiones pareciera que el infortunio hubiera querido colocar una venda a los ojos del historiador mediante la destrucción de las principales fuentes que hubieran permitido construir un estudio extenso sobre un tema de interés. En otras, será el propio bagaje profesional de los especialistas y su contexto vital los que limiten la mirada sobre unos elementos y provoquen la indiferencia ante otros, que se tornarán invisibles ante su incisiva pupila. Como ejemplo de lo anterior podemos traer a colación la Historia de las Mujeres, una corriente historiográfica dinámica, pujante y ya con una dilatada trayectoria, que viene a dar luz y voz a la mitad de la humanidad tradicionalmente obviada por las principales líneas de investigación histórica.

Ahora pareciera incoherente comenzar cualquier tesis en la que premeditadamente se excluyese a la mitad de las personas involucradas, restando valor a sus contribuciones e, incluso, a su propia existencia; y, sin embargo, esta ha sido la tónica acostumbrada en los albores de la Historia como ciencia. Esta actitud se ha descubierto errónea y la Historia de Género viene a completar así las deficiencias que este abandono causa en unos saberes pretendidamente universales.

No es excepcional aquel contexto en que, cual callejón sin salida, parecen agotarse las fuentes necesarias para realizar un estudio significativo, hasta tal punto que, definitivamente, el escollo se hace insalvable. En otras ocasiones, gracias al desarrollo de la ciencia histórica y una apertura en sus enfoques, se ha conseguido el acceso a unas fuentes anteriormente ignoradas por no ubicarse dentro del canon dominante pero que nos permiten avanzar en el camino deseado. Un ejemplo lo descubrimos en la prensa y su potencial uso como fuente histórica. En un principio, dado su carácter ligero y cotidiano era considerada como mera anécdota, un elemento que servía para ilustrar lo expuesto por otras fuentes; pero su esencia de ser el pulso vivo de la sociedad en la que se desarrolla, le concede valor histórico, una realidad de la cual ya se hizo eco Tuñón de Lara, "la prensa es 
de valor inapreciable. Pero en otras secciones que aquellas que suelen ser objeto de nuestra predilección. Se trata de los reportajes, de los sucesos, de los anuncios, de los espectáculos, de las crónicas de sociedad"1.

Igualmente tenemos presente que no basta con un análisis cuantitativo de la información, sino que hay que profundizar en el aspecto cualitativo, como por ejemplo considerando teorías de género tales que el arquetipo viril. Según este concepto, se destacaría la atribución de elementos positivos a lo masculino, mientras que lo femenino iría acompañado de adjetivos negativos, que venían a corroborar el fracaso general de las mujeres respecto al éxito que representan los hombres ${ }^{2}$. Y es que "los estudiosos [...] se han centrado preferentemente en los protagonistas y acontecimientos políticos y en las publicaciones que corresponden con este enfoque, y han menospreciado los medios de comunicación más masivos y la publicidad que los financia", limitando los resultados obtenidos.

En sus inicios la prensa se fue configurando como un medio de información y propaganda exclusivamente política. Estas autodenominadas publicaciones serias no asumieron la aparición de una nueva variante que, según glosaban los profesionales de la época, desdeñaban la función que tenían encomendada, dando pábulo a informaciones diversas y de carácter apolítico. El surgimiento de la prensa moderna vino a romper los moldes establecidos, si bien su objetivo no era relegar la información política, sí lo era aumentar el rango periodístico hacia el esparcimiento y un mayor interés del lector.

Es durante el reinado de Isabel II cuando se configura el periodismo noticiero gracias en parte a nuevos avances técnicos como el ferrocarril y el telégrafo, que permitían una mayor celeridad en la difusión de las noticias. La presunción de imparciales les valió las críticas de la prensa de partido, mayoritaria en la época, a cabeceras como Las Novedades (1850) o La correspondencia (1860) ${ }^{4}$. Sin embargo, cabeceras tradicionales (como El Imparcial [1867], El Globo [1875] o El Siglo Futuro [1875]) adoptaron en sus páginas la innovación que representaban tras observar que no sólo no habían desaparecido, sino que van conquistando un éxito no previsto, adoptando un lenguaje sobre constantes mejoras, ampliación de tiradas, anunciantes, acercándose a la idea de empresa, pero sin dejar de lado su

1. M. TuÑón de LARA (1973), 140.

2. A. Moreno SÁrda (2007), 211-212.

3. A. Moreno SÁrda (2006), 8.

4. M. ${ }^{\text {a }}$ C. Segane (1977), 272-273. 
labor inicial y relaciones con el poder ${ }^{5}$.

Estas nuevas cabeceras, al configurarse como empresas teóricamente emancipadas de los poderes políticos, buscaron la forma de rentabilizarlo, para lo cual iban a recurrir a la fórmula de acrecentar las ventas gracias a un contenido y precio atrayentes. Para incrementar los beneficios se sondearon nuevas formas de negocio más allá de la comercialización de ejemplares, irrumpiendo con fuerza un nuevo elemento que pronto se adivina esencial: la publicidad. Lo notorio de este proceso es el protagonismo que adquieren nuevas formas narrativas, que directa o indirectamente ubican en el espacio público a elementos que tradicionalmente no habían estado bajo el foco de atención, como las mujeres, determinadas clases sociales, ciertos ambientes ciudadanos: "Hechos, valores, emociones: sobre este trípode descansa la razón de ser de la prensa moderna"'.

En este contexto, la Restauración monárquica crea cierto marco de estabilidad política y prosperidad económica que favorecerá el desarrollo y extensión de diversas empresas periodísticas ${ }^{7}$. La extensión de la prensa de masas, caracterizada por la financiación publicitaria, un precio más bajo y un aumento de tirada, va a ser tomada con ciertos reparos por investigadores como Timoteo Álvarez, que afirma que dicha prensa no llegó a consolidarse como consecuencia del fracaso de la Revolución Industrial en el país, lo cual no crearía condiciones necesarias para dicho desarro$110^{8}$. No obstante, es innegable la relevancia que van adquiriendo dichas publicaciones: "Aunque a mucha distancia en calidad e importancia de la prensa francesa e inglesa, la española se transforma, desarrolla y consolida extraordinariamente en el último cuarto de siglo" . Durante este proceso, aquellas cabeceras que se consolidan con una estructura empresarial van a gozar de mayores probabilidades de éxito ${ }^{10}$. Estas industrias pueden llegar a ser muy poderosas, pero "lo cierto es que predominaban las pequeñas empresas. Muchas de estas publicaciones tenían muy corta vida. Además, el analfabetismo restringía mucho el público potencial"11. Debemos recordar que a principios del siglo XIX el periódico era un producto caro, con un público objetivo muy concreto entre los grupos sociales que se lo podían

5. J. T. Álvarez (1981), 56.

6. V. M. Lezcano (1979), 201-220.

7. M. Llanas Pont (1996), 11-54.

8. J. T. Álvarez (1981), 200.

9. M. ${ }^{\text {a }}$ C. SeOANe (1977), 399.

10. M. ${ }^{a}$ C. Seohne y M. D. Saiz (1998), 254.

11. A. Pizarroso Quintero (1994), 288. 
permitir y mostraban interés en sus contenidos; con el avance del siglo, la adopción de la estrategia mercantil y la incorporación de nuevos contenidos, se abarcará un público de mayor calado entre las distintas capas sociales, desde la pequeña burguesía hasta las clases populares ${ }^{12}$.

Centrándonos en los contenidos, hemos mencionado que la prensa otorga voz a los otrora silenciados, y lo hace en aquellas secciones que en un principio se configuran con una función informativa y de entretenimiento, quizá morboso pero inocente en su difusión: noticias judiciales y reseñas de sucesos. Estamos ante una apuesta de la prensa moderna dentro de su estrategia de captar la atención de los posibles compradores: "Le sensationnel est ainsi le péché originel qui marque la naissance de la presse moderne"13. Estas informaciones van a jugar un papel relevante dentro de la estrategia empresarial, hasta tal punto llega su triunfo que "a finales de siglo [XIX] la información sensacionalista de crímenes con frecuencia repugnantes tenía mucho mayor lugar en los periódicos serios, no especializados en sucesos, que en nuestros días"14. A pesar de su carácter estas narraciones nos consienten el acceso a ámbitos privados, laborales, cotidianos, que de otra manera no sería posible. Ello nos confiere un gran potencial de indagación y análisis como ya probamos ${ }^{15}$, siendo conscientes de que ninguna fuente histórica es perfecta y necesita ser trabajada con cautela. Más allá del sesgo negativo que las informaciones de sucesos refieren, no ponemos en tela de juicio que estamos ante una fuente de primer nivel.

Entre las principales cuestiones que debemos tener presentes cuando nos acercamos a las noticias de sucesos publicadas durante el siglo XIX es que estas se encuadran dentro del discurso concreto de relaciones de poder, actuando como un mecanismo de control que reproduce el sistema de dominación vigente y que coincide con el burgués ${ }^{16}$. Esto nos descubre aquellos hechos que rompen las reglas, las costumbres sociales y que suelen ser reflejo de la ruptura del orden establecido. El sistema de autoridad y confianza se refuerza mediante mecanismos y discursos reiterativos como la persecución por parte de las autoridades en aquellos casos que el victimario haya conseguido huir; felicitaciones a los buenos ciudadanos que

12. P. Albert, J. M. Guash y J. J. Sánchez Aranda (1990), 46.

13. G. Awad (1995), 159.

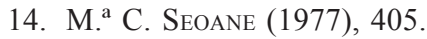

15. V. J. Ortega Muñoz (2018).

16. Ibidem, 375-376. 
han cumplido con su labor social en una situación crítica; relación de los detenidos tras el hecho criminal, exposición de una imagen de eficacia, etc.:

Es por ello que dichas informaciones sirven para marcar la línea divisoria entre el bien y el mal, entre aquellas actitudes y comportamientos que son los adecuados y los otros que deben ser erradicados. De este modo cualquier lector, independientemente de la clase social, puede entrever que comportamientos son premiados y cuáles son perseguidos y castigados, sirviendo de advertencia ${ }^{17}$.

Dentro del amplio espectro que engloba el concepto sucesos, creemos de especial interés el examen de las noticias de suicidios publicadas durante la Restauración española. Así, centramos nuestro estudio en dos cabeceras referentes en sus provincias e influyentes más allá de sus límites regionales, se trata de La Unión Mercantil, editada en Málaga y de La Vanguardia, en Barcelona. Ambas exhiben características análogas: ser impresas por grupos burgueses en pujantes ciudades mediterráneas y estar incluidas dentro de la indicada prensa moderna.

\section{EL SUICIDIO}

Desde muy pronto el recelo a que se pudiera producir una amplificación de la práctica por emulación induce cautelas a la hora de la publicación de informaciones relativas al suicido, cuando no directamente su omisión. Esta circunstancia nos limita en cuanto al número de noticias existentes, y si bien en teoría deberían ser escuetas como una gran parte de las informaciones de sucesos, hemos localizado un relevante número que presentan una extensión considerable.

En cuanto al suicidio como fenómeno sanitario y/o sociológico se instituye durante el siglo XIX un enérgico debate entre la naciente psicología y las autoridades, en el que la primera trata de medicalizar cuestiones concernientes a homicidios y los propios suicidios. Es sabido que el principio de la psicología es seguido por un proceso de consolidación y extensión de su campo de acción que encuentra en los casos de graves asesinatos y conductas consideradas irracionales, una justificación basada en la aseveración de la enfermedad de sus protagonistas, lo que sería realmente el origen del fatal desenlace, por tanto, no se trataría tanto de penar al criminal, como

\section{Ibidem, 176 .}


de interponerse con unos tratamientos mentales adecuados. Así, "uno de los debates más importantes sobre el suicidio en la literatura psiquiátrica del siglo XIX fue si debía ser considerado como una enfermedad mental o como el acto voluntario de un individuo mentalmente sano" 18 , lo cual era la esencia de una ofensiva por conquistar competencias entre estos nuevos profesionales de la medicina, que ambicionaban asumir la tutela de dichos individuos, que tradicionalmente habían llevado jueces y abogados.

Dentro del debate dialéctico no puede obviarse un actor vital en la España de la época como es la Iglesia. Numerosos autores coetáneos señalaban la pérdida de valores religiosos como una de las principales causas del suicidio y como consecuencia, el desarrollo de esos valores religiosos resultaría la acción más efectiva para evitar su proliferación ${ }^{19}$.

La incomprensión hacia el suicida y el hecho en sí es una constante y por más que se busquen explicaciones, estas no siempre aparecen, acudiendo en numerosos casos a una contrariedad mental del finado: se suicidó porque estaba $1 \operatorname{loco}^{20}$. Cuando no aparecen, ya sea por la premura del hecho y la inmediatez de la publicación, o porque no se haya encontrado explicación en el marco de los parámetros decimonónicos, es frecuente apelar a la locura como justificante. "Y es que cuando no existe «razón», la «locura» es un argumento válido y consolador en la medida que expone de forma descifrable algo de por sí ininteligible. A la vez que evade formar preguntas de mayor calado" 21 .

Esta tendencia se depura y se hace predominante durante los siglos XIX y XX con las teorías psicopatológicas y sociológicas como preponderantes a la hora de interpretar y analizar los suicidios, elevando a la enfermedad mental como el factor primordial de suicidio. Estas corrientes restringen los alegatos de los sucesos a causas internas y acotadas, considerándolos hechos biológicos, aislados y por tanto sin contexto histórico o social:

Juego bastante resbaladizo, ya que a la vez que exculpa y justifica, desdibuja e invisibiliza la (posible) agencia del sujeto que lleva a cabo un suicidio. Desvinculando radical y arbitrariamente el acto del suicidio, del proceso de producción subjetivo e intersubjetivo en que se inscribe ${ }^{22}$.

18. J. J. Plumed Domingo y L. Rojo Moreno (2012), 151.

19. Ibidem, 163.

20. J. M. De Miguel (1970), 35.

21. V. J. Ortega Muñoz (2016b), 566.

22. M. ${ }^{a}$ del M. Velasco Salles y M. Pujal i Llombart (2005), 136. 
El tratamiento del suicidio como enfermedad no hace prescindibles los elementos correccionales, ya que el cambio de paradigma no lleva aparejada una necesaria desaparición del castigo y el estigma. Esta contradicción ha sido explicada en parte por la continuidad de la concepción cristiana de la vida, sus dogmas y creencias, fuertemente enraizada en nuestra cultura ${ }^{23}$. Viene al caso traer a colación cómo el cristianismo a finales de la Edad Media negaba la sepultura cristiana, el duelo, las oraciones y las misas a aquellos que habían muerto de forma violenta, especialmente en casos de suicidio $^{24}$. Esta mácula no solo acompañaba a la persona fenecida, sino que se hacía extensiva al total de familiares.

En España la medicina estuvo en sus inicios fuertemente condicionada por el catolicismo, identificando la voluntad con el concepto de alma, y el suicidio como el fracaso de la voluntad del individuo que sin la fortaleza que un cristiano debe tener, caía en el peor de los pecados ${ }^{25}$.

Por otro lado, el suicidio no es una decisión repentina, es trascendente y obliga a que exista un periodo de reflexión sobre la vida y la muerte, ya sea consciente o subconscientemente. Esta ardua deliberación íntima permite en ciertos casos advertir cambios de actitud y personalidad que indicarían la proximidad de la irrevocable disposición, pero que podría confundirse con otros elementos dependiendo de las circunstancias. "La persona suicida típica presenta [...] sentimientos de desesperación e impotencia; sentimientos de agotamiento físico o psicológico; sentimientos intensos de ansiedad, tensión, depresión, rabia o culpa; sentimientos de caos y desorganización" 26 .

Otra visión sobre esta práctica nos la ofrece Durkheim, un clásico y referencia ineludible, gracias a su conocida obra El suicidio. Este autor limita las condiciones ajenas al sujeto como la economía o los conflictos armados, para llegar a la conclusión de que existen sociedades que presentan rasgos que las hacen poseedoras de una mayor tendencia suicida que otras, caracterizadas según su opinión por mostrar incoherencia o contradicción en el desarrollo de sus leyes y normas ${ }^{27}$.

Observamos un cambio en el discurso vigente durante el segundo tercio del siglo XIX, aparte de todos los condicionantes que estuvieran

23. G. H. Amador Rivera (2015), 95.

24. I. Gómez de Rueda (1997), 181.

25. J. J. Plumed Domingo y E. J. Novella (2015), 65.

26. F. Miralles y A. Cano (2009), 191.

27. A. F. Palacio (2010), 10. 
presionando en los individuos y las situaciones que tuvieran que gestionar, el responsable último seguía siendo el individuo, la decisión última sobre su vida era su decisión ${ }^{28}$.

Ya en el último cuarto del siglo XIX se van a imponer en España las teorías degeneracionistas, defensoras de la causa hereditaria de la enfermedad mental, la cual se veía agravada por acciones como la ingesta de alcohol. Estas teorías explicarían el declive de la civilización europea de fin de siglo a través de la biología y las enfermedades sociales, entre las que figuraba el suicidio ${ }^{29}$. Así, se incluye la existencia de un fondo emocional detrás de acciones como el suicidio, estimulando aquellos sentimientos incontrolados la posible realización de acciones perniciosas.

Desde este punto de vista, el individuo degenerado tendía a actuar sin control alguno sobre sus impulsos emocionales, ya que su desequilibrado psiquismo padecía una anomalía hereditaria que le impedía ejercer el libre albedrío sin que su experiencia subjetiva y sus convicciones morales pudieran alterar el curso de los acontecimientos ${ }^{30}$.

El degeneracionismo acabó imponiéndose en España entre las explicaciones sobre la monomanía, adquiriendo un papel notable en el fortalecimiento de la psiquiatría como colaborador en los tribunales. "Las ideas degeneracionistas llegaron a considerar incurable a un verdadero enfermo mental, puesto que viviría condicionado por cuestiones biológicas heredadas ante las que el margen de acción era exiguo" ${ }^{31}$. Se restringe así la verificación de sus métodos para el tratamiento de dichos enfermos, lo que no obsta que se aprovechara su vertiente de análisis biológico para amplificar el control social mediante el análisis de los caracteres físicos, que corroborarían estar ante la presencia de un enfermo mental o una persona cuerda.

Las diversas teorías médicas-psicológicas que florecen durante el siglo XIX nos hablan de una constante evolución, investigación, reelaboración del discurso, que no pudo hacerse más allá de las circunstancias que permiten la propia condición humana. Así, se aprecian problemas para tomar distancia por parte de los profesionales médicos del momento respecto al enorme significado filosófico, religioso, moral y cultural de conductas

28. J. J. Plumed Domingo y E. J. Novella (2015), 69.

29. Ibidem, 77.

30. Ibidem, 79.

31. V. J. Ortega Muñoz (2016b), 563. 
autodestructivas. "Esto se puso especialmente de relieve [...] cuando se tomó conciencia de lo que significaban las conductas autodestructivas como fenómenos que cuestionaban el orden establecido" 32 .

Dentro de la incomprensión general, según la situación de los fallecidos, así como la personal de los lectores, podía existir un mayor o menor grado de empatía, si bien habitualmente era escasa. Sí apreciamos cierta simpatía hacia aquellos casos que se creen entender, si bien la suicida no habría sido lo suficientemente fuerte para sobreponerse a la situación que habría engendrado su decisión. Esta idea, aparte de la desagradable muerte acaecida, con el desasosiego propio de toda acción que rompe la normalidad cotidiana, lleva aparejada un sentimiento de alivio y reafirmación en la propia fortaleza, pues en determinados casos, con una circunstancia asimilable a la de la finada, se consigue sobreponer a los obstáculos. Desde otro enfoque, simultáneamente se está prejuzgando una debilidad (que en la mujer sería intrínseca) para afrontar la realidad diaria.

\section{INFORMACIÓN DE SUCESOS, SUICIDIOS Y MUJER}

Los estudios sobre los suicidios centrados en la evolución de la ciencia psiquiátrica, así como en la búsqueda de las causas que expliquen los mismos, han prestado escasa o nula atención a la posible existencia de una diferencia de género. Según la Dra. Montesó hemos de retroceder hacia los años sesenta para atisbar análisis que localizan este tipo de diferencias, pero las conclusiones de los mismos parecen destacar las variables socioculturales y económicas como el origen de las mismas. Será en los ochenta cuando comience la aceptación de la existencia de diferencias basadas en componentes hereditarios y hormonales, así como ambientales y culturales; concurriendo una corriente desde los noventa hasta nuestros días que reconoce implícitamente la existencia de diferencias de género ${ }^{33}$.

Las mujeres durante el siglo XIX aparecen confinadas en el ámbito privado, estando reservado el público para los hombres, actores de la política, economía, medios de comunicación, ciencia, etc. A las mujeres se las circunscriben al hogar y la crianza de los hijos reduciéndose su campo de acción a una actuación en la sombra. El patriarcado imperante anulaba a la mujer, no tenía en cuenta sus anhelos ni sentimientos, aspiraciones o capacidades, etiquetándola de ser irracional, tendente a dejarse guiar por los

32. J. Martínez Pérez (2001), 65.

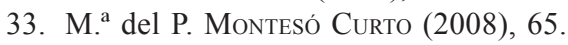


sentimientos y por tanto peligrosa en cuanto pretendiera poner en práctica cualquier actividad racional. Sus ideas podían fluir, pero no propagarse ya que "si hace sonar su voz en un tono estridente, no permitido, si tan sólo reclama un derecho a la palabra, ésta será interpretada y recogida por el oído experto del médico, del psicoanalista, del psiquiatra" 34 .

Retomando una idea anterior, aquella sobre el momento en que se relacionaron las pasiones y las enfermedades mentales, y por tanto el suicidio, al ponerlo en paralelo a la caracterización de la mujer como ser pasional, puede llevar a la idea de una especial predisposición hacia la locura y el suicidio. Además, todo ello se reviste de un carácter peyorativo asociado al término "pasiones" que bien podría ser sustituido por el de "emociones" ya que el primero aparece íntimamente ligado a la subjetividad y lleva aparejada una carga moralizante obvia ${ }^{35}$.

Estudios sobre la mujer y el suicidio contrarrestan la imagen oficial y nos descubren una realidad en la que, una y otra vez, son las tensiones subyacentes del clima de violencia que empantanan sus relaciones familiares las causas de la decisión de quitarse la vida ${ }^{36}$.

Cuantitativamente, contradiciendo los estudios que muestran datos similares entre los protagonistas del suicidio, las reseñas analizadas a lo largo de nuestro estudio nos indican una diferencia sustancial en cuanto a representatividad, los hombres son mayoría, ocupando las mujeres un papel minoritario entre dos y cuatro veces menor. Esta situación puede deberse a dos factores, uno, que realmente exista un número pequeño de mujeres que deciden terminar con su vida, otro, la existencia de una infrarrepresentación por no considerar de interés dichas informaciones, publicando únicamente aquellos casos que llamen poderosamente la atención. Esta segunda hipótesis podría verse reforzada si tenemos en consideración que las formas de abandonar este mundo suelen ser más espectaculares cuando son efectuados por hombres.

Así la ingesta de venenos, ahogamientos, lanzamientos al vacío, e incluso disparos en la sien, podrían ser las formas más habituales de morir, si bien en el último caso, factible por la fuerte presencia de armas de fuego en la sociedad del momento, es una rara avis en el conjunto de ejemplares examinados, si bien apreciamos tendencias hacia el morbo manifestadas a través de una profusa redacción trufada de detalles.

34. R. M. Rodríguez Magda (1994), 73.

35. A. Diéguez (2010), 41.

36. M. Fernández Labbé (2008), 4. 
Desde Melilla. Malagueña que se suicida. Muy conocida entre las personas de carácter alegre de Melilla, era una individua de Roda, más conocida por el nombre de Consuelo y el de guerra "La Aviadora", de unos 28 a 30 años de edad, natural de Vélez-Málaga, soltera y con una hija que vivía al lado de su abuela materna, que reside actualmente en Málaga, y vive en la calle de Cabello. [...] La noche del suicidio salió "Consuelo" con una compañera y unos amigos marchando de juerga a Vista Alegre. Regresaron todos a la casa al amanecer y pretextando la muchacha que iba a cambiarse de ropas, entró en su cuarto y cogiendo un revolver que tenía, salió de la vivienda marchando a pasear por la cañada de Rostrogordo. Al llegar al barranco de Horcas Coloradas, sacó el revólver, disparándose un tiro en la sien derecha. A la detonación acudieron un sargento del regimiento de Ceriñola y varios individuos de la Policía Indígena, que se apresuraron a auxiliarla y trataron de conducirla a la enfermería próxima; pero la infeliz muchacha falleció a los pocos momentos. [...] Se dice que la suicida padecía frecuentes ataques de histerismo, sufriendo, su carácter grandes y rápidas alternativas. [...] Concha ha sido enterrada en el Cementerio Civil ${ }^{37}$.

En el texto anterior, si tratamos de descubrir el porqué de Consuelo para asir el revólver y poner fin a su vida, la redacción de la noticia no facilita ningún indicio. La extensa descripción de la vida y personalidad de dicha mujer, la existencia de una hija al cuidado de la abuela, la vida alegre y la omisión de la existencia de un cónyuge, muestra un escenario atípico y que no concuerda con las prácticas sociales admitidas. El que en ningún momento se discuta que incitaciones podrían concurrir contiguo al relato glosado, nos promueve a especular sobre la posibilidad de que el código está claro entre periodista y lector: una mujer con un modo de vida tan alejado de la ortodoxia social, no extraña que llegue a anhelar concluir con la misma, poniendo fin al desorden vital. Es más, se hace mención expresa a la histeria y cambios de ánimo de la protagonista, una categorización que apenas localizaríamos en los casos de suicidio masculino, pues son atribuciones propias de las mujeres. Se ofrecería así una muestra de las lúgubres consecuencias que pueden sufrir aquellas mujeres que renuncian a las normas sociales, funcionando como un modelo ejemplarizante para las lectoras.

El acceso a productos tóxicos propios de los hogares decimonónicos, independientemente del nivel socioeconómico, y las actividades que en ellos se llevaban a efecto, facilitan una tarea que debía provocar un plá-

\section{La Unión Mercantil, 20/1/1918.}


cido descanso eterno sin despertar recelos con anterioridad a su puesta en práctica. El inconveniente de esta elección es el posible error de medida, el hallazgo a tiempo y el tratamiento médico que hiciese frente a la dosis ingerida, salvando in extremis a la suicida ${ }^{38}$.

Acaba de morir en París una mujer, Leona D., famosa por su hermosura y por el fastuoso lujo que en todas ocasiones desplegaba. Hacía ya algún tiempo que había desaparecido de ese torbellino de la vida parisién y que su nombre había caído en el olvido. Atacada por la viruela su rostro quedó con tan horribles huellas de la enfermedad, que aquella mujer tuvo que contentarse con vivir de los restos de la fortuna que antes derrochaba a manos llenas. La miseria fue estrechándola cada día más, hasta que, presa de la más profunda desesperación, puso fin a su vida tomando un veneno, para librarse de los sufrimientos presentes y de los recuerdos amargos que la asaltaban de los pasados años. Cuando acudió el médico llamado por los vecinos, la encontró ya cadáver. Una lección más ${ }^{39}$.

Observamos un claro valor moralizante no estrictamente necesario en la anterior noticia, muy del agrado de la prensa burguesa. Es objeto de atención la historia de una mujer rica y bien parecida que por varias circunstancias ve completamente alterado su día a día. La enfermedad y la pérdida de la belleza se muestran como hechos trascendentes que cambian en un breve lapso de tiempo la cotidianidad de la protagonista. El periodista se sirve del trágico final para recordar en pocas palabras lo efímero del éxito y la riqueza, la necesidad de tomar las riendas de la vida para no acabar de igual modo, y disponer de una base material y moral sólida que actúe como red ante lo incierto del futuro.

Debemos recalcar que en nuestro recorrido por las páginas de $L a$ Unión Mercantil y La Vanguardia sólo aparece un caso en el que no logra culminar su autodestrucción, siendo el método elegido la precipitación a las aguas del Guadalquivir.

POR NO SUFRIR AL MARIDO. Ha sido detenido un sujeto llamado Elías Álvarez, marido de Isidora García. Esta se arrojó al Guadalquivir con ánimo de suicidarse y los testigos han confirmado que el Elías daba a la infeliz mujer muy malos tratos ${ }^{40}$.

38. M. Fernández Labbé (2008), 3.

39. La Vanguardia, 20/12/1883.

40. La Unión Mercantil, 14/6/1918. 
En pocas líneas tenemos conocimiento del intento de suicidio, aunque no queda despejado el desenlace, la redacción ofrece la eventualidad de que se salvara. La causa de la tentativa está completamente identificada y son los malos tratos que recibía, un escenario que se repite en otras tipologías de noticias de sucesos donde observamos agresiones, violaciones, insultos, intentos de asesinato y homicidios. No obstante, hay que poner de relieve la actitud de las cabeceras objeto de nuestro estudio que sitúan el foco en "una vergonzante situación pero que es capaz de denunciarla y exponerla cual es, aunque siempre desde un punto de vista paternalista, protector, machista y hasta cierto punto irónico y frívolo" ${ }^{\text {. }}$.

Las contrariedades de pareja, de amores o familiares, asoman asiduamente como explicación de los suicidios protagonizados por mujeres. Percibimos una vez más el componente sentimental como un mecanismo desestabilizador en la mujer que, si esta no es capaz de dominar, podría resultar en graves contrariedades. Esta actitud encubre mecanismos de control y reclusión hacia las mujeres. "[...] el Estado se arroga la capacidad de dictar la sexualidad permitida, estableciendo y regulando las correctas relaciones ente géneros, indicando la división laboral y vital, a la vez que trata de controlar el propio cuerpo y mente de los ciudadanos" ${ }^{\prime 2}$.

Suicidio de una joven en Algeciras. En la esquina de la calle Nueva y la de San Antonio vivía María López Vera, preciosa joven que apenas contaba 18 años, de buenas costumbres y muy trabajadora, la cual sostenía relaciones amorosas con un joven de poca más edad. Habiendo sido llamado al servicio de las armas, tuvo que ausentarse, con cuyo motivo se despidió de la familia ofreciendo escribir a menudo a fin de saber de todos con frecuencia. Efectivamente, se cambiaron entre los amantes las primeras cartas; pero a poco se cortaron las relaciones por haber dejado el de escribir, transcurriendo así algún tiempo. Creyéndose olvidada y, por tanto exenta de todo compromiso, aceptó el ofrecimiento de un nuevo pretendiente, siguiendo de este modo hasta el día en que, de regreso su primer amante, se presentó en casa de la joven, volviendo a requerirla solicitando su amor como en otro tiempo. Nada pudo conseguir a pesar de sus repetidas instancias, pues ella, tanto por estar resentida como por haberle cobrado cariño al segundo, se negaba en absoluto a complacerle. En tal situación, intervienen los padres de la joven queriendo obligarla a todo trance a reanudar sus antiguas relaciones, dando por resultado que tomara la fatal resolución de suicidarse, como efectivamente lo llevó a

41. V. J. Ortega Muñoz (2012), 8.

42. V. J. Ortega Muñoz (2016a), 277.

(C) Baetica. Estudios Historia Moderna y Contemporánea, 40, 2020, 233-258. Facultad de Filosofia y Letras, Universidad de Málaga. Departamento de Historia Moderna y Contemporánea 
cabo arrojándose a una poza del río Ancho y muriendo ahogada sin haber sido posible salvarla ${ }^{43}$.

En el anterior texto apreciamos rasgos destacables, por un lado, la juventud, siempre es más traumática la marcha de alguien que por edad no debería irse, por otro, la belleza de la víctima, considerándose cualidades que acrecientan el drama por su pérdida. Si bien encontramos varios niveles de edad, imperan aquellos protagonizados por jóvenes, a las que, repetimos, se ensalza su belleza física.

En relación a las relaciones amorosas, la mujer no dispone de su voluntad ni de su propio cuerpo. Tras cambiar de pareja por la dejación de su anterior novio, el regreso de aquel coincide con la circunstancia de que existe un nuevo pretendiente, confirmando que ella no decide. La presión del joven retornado, junto a los padres de ella, imposibilitan su relación actual y la abocan a un trato concertado en el que nada puede opinar. Es ante esta perspectiva de control cuando se descubre la aspiración de perder la vida. Se asume como una huida de un destino ya escrito, pero no con trazos tan firmes que no consientan efectuar un último acto de rebeldía, un recurso desesperado y definitivo.

SUICIDIO EN RONDA. En el kilómetro 69-824 de la línea de Ronda, se ha suicidado arrojándose al paso del tren, una preciosa joven de 24 años, llamada Ana Pérez Almagro, hija de una persona muy conocida en Ronda. El cadáver quedó destrozado, permaneciendo cuatro horas sin que nadie se apercibiera del suceso. Se dice que el suicidio obedece a contrariedades amorosas ${ }^{44}$.

El honor de la familia recae en las mujeres, funcionando como un mecanismo que consiente intervenir sus relaciones e instintos. La presión social ante los comportamientos no aprobados puede hacer recapacitar que, ante un escenario de deshonor, es tan grave y serán tantos los comentarios y habladurías, que una reacción autodestructiva se antoja algo positivo o por lo menos una opción viable. Así, la concepción decimonónica del honor "facilita el control integral de las hijas, optar por un pretendiente conveniente a los intereses familiares y tomar medidas en caso contrario con el respaldo social"'45. 
ABANDONADA POR EL NOVIO. En Alcoy ha intentado suicidarse una joven muy bella tomando una disolución de fósforos. La expresada joven atentó contra su vida a causa de haberla abandonado su amante, por quien ella huyó, según se dice, de la casa paterna ${ }^{46}$.

Ante la imposición emerge el recurso a la huida con el amante, generalmente a edades tempranas, buscando una vida separada de los padres que de otra manera no les admitirían estar juntos. Es esta una medida aventurada, aunque según hemos podido comprobar en otras tipologías de sucesos como los "raptos voluntarios", es una fórmula conocida y practicada, pero no deja de ser un hecho noticiable, como también lo son las numerosas veces que no acaban como deseaban los protagonistas, sino con la joven en la casa de los padres y el joven, al que se le supone inductor y culpable único, en la celda. El deshonor, así como las más que seguras represalias, pueden hacer reflexionar a la protagonista sobre el suicidio como salida, convencida de no soportar la vuelta a la reclusión familiar, o en algún caso extremo, la reclusión en un centro eclesiástico tal que un monasterio. En esta ocasión la fuga no ha tenido éxito, no por la intervención de las autoridades, sino por el cambio de parecer de su amante. Ante este panorama, pocas soluciones honrosas se le presentaban. El estigma social aparece como una fuerte motivación para querer desaparecer definitivamente.

Una joven que trabajaba en una fábrica de Sabadell, a orillas del río Ripoll, se suicidó arrojándose desde el puente llamado de la Salud. Los motivos de tan desgraciado suceso obedecen, según parece, a que fue abandonada por su novio, después de dolorosa seducción ${ }^{47}$.

Como venimos diciendo, la imagen transmitida refuerza el estereotipo de mujer débil, pasional y llevada fuera de toda razón por motivos ilógicos y emocionales. El desamor, tanto por la tristeza de la pérdida de una oportunidad deseada, como por la situación en que deja a la persona frente a las habladurías de la sociedad que la va a juzgar por no seguir adecuadamente el camino marcado, es una motivación habitualmente expresada como fuerza inductora del suicidio.

Una joven de 16 años de edad que servía en calidad de criada en una casa de la Bajada de San Miguel, se suicidó tomando una cantidad de sal de acederas.

46. La Unión Mercantil, 20/11/1895.

47. La Vanguardia, 20/10/1883. 
Los móviles que tuvo para poner fin a su existencia, parece que fueron amores contrariados. El juzgado procedió al levantamiento del cadáver, ordenando que fuera trasladado al cementerio del Sud Oeste ${ }^{48}$.

Esa presión para ofrecer siempre una buena imagen y cumplir los códigos de conducta y honor llevan a realizar actos desesperados cuando acciones consideradas faltas tienen consecuencias difíciles de ocultar. Es el caso de un embarazo fuera del matrimonio, fuente de un gran deshonor y que puede arruinar no solo la reputación de la embarazada sino cualquier aspiración de futuro. Frente a esta perspectiva no es extraño que se pueda recurrir a medios comprometidos para evitarlo. Por ejemplo, acudiendo a sustancias abortivas, obviamente fuera de la ley, con el riesgo de ser descubierta, además de las altas probabilidades de tener consecuencias perjudiciales para su salud.

Otra opción sería optar por el suicidio. Acabada la vida, acabada la dificultad, opción condicionada por un entorno asfixiante para el desarrollo afectivo y sexual de la mujer.

Suicidio por amor. Un drama ocurrió hace dos días en Esparraguera (Barcelona). [...] una agraciada joven de veinticuatro años llamada Elisa, viuda hace año y medio, vivía en dicho pueblo con una niña de corta edad, atendiendo a las relaciones amorosas con un chico de la población a quien amaba apasionadamente y con quien debía contraer matrimonio hace cuatro días. Momentos antes de realizarse sus alegres ilusiones cuando el novio se dirigía en su busca para conducirla a la iglesia, el padre de ella se interpuso en su camino y le insultó repetidas veces hasta originar una cuestión, de la que, después de mutuas increpaciones, el joven se retiró a su casa vestido con su traje de boda y resuelto a no pensar más en la viuda que tanto le quería. Al tener ésta conocimiento del suceso, su desesperación no tuvo límites y pensó resueltamente poner fin a su existencia. Para ello envió a su sirvienta por ácido clorhídrico, pero al intentar bébelo, aquella le arrancó de las manos la botella, quebrándose ésta y vertiéndose todo el líquido que contenía. Al ver que no pudo lograr su propósito, la infeliz se echó a la calle sin que su criada lo advirtiera o lo pudiese evitar, y con su traje de fiesta, [...] corrió desesperada y loca a estrellarse contra unas rocas, lanzándose desde el elevado puente hace poco construido en la carretera de Madrid [...] Al verificarse la autopsia de la suicida se descubrió en su seno el germen de un nuevo $\operatorname{ser}^{49}$.

48. La Vanguardia, 20/2/1901.

49. La Unión Mercantil, 20/9/1887. 
Vuelve a ponerse de manifiesto el control de género en un episodio en que el padre evita la boda de una joven viuda. Puede que al progenitor no le agradara la pareja de su hija, aunque igualmente podría tener conocimiento de que su hija estaba encinta y no quedara de acuerdo con la unión. La joven Elisa, ya viuda y con una niña, entiende que el ser de nuevo madre, y en esta ocasión fuera del matrimonio, solo va a extender las desdichas propias de vivir en una sociedad poco tolerante, concurriendo varios estímulos para inmolarse. Frustrada la primera tentativa por la interposición de la criada, acude al medio más próximo, que no es otro que el lanzarse por un puente. Que el episodio se provoque el mismo día de la boda, y estando ella todavía vestida con el traje nupcial, le procura un mayor impacto periodístico, de ahí la extensión del informe y la abundancia de pormenores.

La situación económica y social no es un elemento concluyente de protección, el influjo del patriarcado y las conductas machistas de vigilancia de las mujeres se extienden entre todas las clases sociales.

UN FOLLETIN EN ACCIÓN. En el pueblo de Lecce (Roma) la escritora israelita Guillermina Levi hija de un acaudalado banquero se enamoró hace meses [de] un joven pasante de notaría que vivía frente a su palacio y la requirió de amores. Levi se enteró y prohibió a su hija aquellas relaciones pues los separaban la religión y la posición social. El matrimonio Levi y su hija emprendieron un viaje por Europa para hacerle olvidar aquellos amores y a su regreso ofrecieron al pasante una cantidad si renunciaba a su hija. Aquel contestó: Cuando sea mayor de edad será mi mujer. "Los padres de Guillermina le encerraron en una casa de campo y al llegar el 20 de enero cumplió su mayor edad [y] se entablaron las diligencias correspondientes. Ayer se casaron vistiendo humildemente y al trasladarse a la casa del marido se oyó un grito de una mujer que se arrojó desde el cuarto piso y cayó sobre Guillermina fracturándole el cráneo y las piernas. La suicida era una joven riquísima. Pasada la luna de miel sobrevinieron los disgustos y ayer el marido apuntó a su esposa con un revólver, arrojándose esta por el balcón. El marido que también se disparó está gravísimo. Su estado es grave $\mathrm{e}^{50}$.

La falta de detalles, añadida a la pertenencia a un grupo social elevado de los protagonistas, que además eran conocidos, hace de esta información, tal como aparece en el titular, asimilable a uno de los folletines que solía incluir la prensa moderna. No uno sino tres suicidios o intentos asoman entre sus líneas: desde la mala fortuna de aquella joven, asimismo de clase

50. La Unión Mercantil, 20/2/1909.

(C) Baetica. Estudios Historia Moderna y Contemporánea, 40, 2020, 233-258. Facultad de Filosofia y Letras, Universidad de Málaga. Departamento de Historia Moderna y Contemporánea 
alta, pero de la cual apenas se señala nada más (ni su nombre, motivación, si falleció o quedó herida, etc.), que cae sobre la escritora hiriéndola, pasando por el altercado entre dos hombres por el futuro de Guillermina. En la narración no surgen en ningún momento los deseos de la protagonista, fundamentalmente lo que importa es el desafío entre el padre y el pretendiente, decidiendo la reclusión de la mujer para sortear su boda. El que será su marido logra, pese a la obstrucción del padre por motivos religiosos y de diferencia de clase social, casarse. El mismo día de la boda acaece el accidente de la otra joven suicida. Al poco tiempo, tras la luna de miel, la relación, por motivos diversos pero que no se indican, deriva hacia la disputa llegando hasta tal punto que hacen acto de presencia las armas, el suicidio de la mujer y el intento de suicidio del marido que, si bien no fallece en el intento, se deja entrever un estado de salud grave que no le permitiría seguir con vida mucho tiempo más.

Aparte del interés por los sucesos expresados, la publicación de los mismos expone las complejas relaciones entre miembros de diferentes clases sociales, y dado el trágico final, justifica veladamente la actitud del padre oponiéndose a la relación de su hija, que habría obrado acertadamente. El otro elemento que deseamos enfatizar es, nuevamente, el control de la mujer, de sus decisiones, de su cuerpo, donde no importa lo que piense porque su pensamiento no es legítimo, no es lógico y por tanto no sabe lo que es mejor para ella. Al igual que en el estudio sobre el suicidio femenino en Chile de Marcos Fernández, aparecen en las informaciones analizadas "una y otra vez las tensiones existentes entre la determinación autónoma de su propia sexualidad y los controles familiares como causales directas de la decisión de autoeliminarse" ${ }^{51}$.

Hemos verificado situaciones de mujeres de todas las esferas apelando a varios procesos para auto-eliminarse. Incluso proporcionalmente emergen más mujeres de clase alta como protagonistas que en cualquier otra tipología de sucesos estudiada. El ser personas destacadas dentro de la sociedad las hace noticiables y merecedoras de una extensión de líneas mayor.

En cuanto a los principales recursos empleados para suicidarse, y con mucha diferencia, nos topamos con la precipitación voluntaria hacia el vacío, con preferencia hacia las vías del tren.

Sensible desgracia. A las tres de la madrugada del 15 del actual ocurrió en Pamplona una sensible desgracia. Próximamente a la hora mencionada se 
arrojó desde el balcón de la casa número $19.4^{\circ}$, de la calle de Zapatería, $\mathrm{D}^{\mathrm{a}}$ Isidra Luna, esposa del conocido industrial "El Madrileño", quedando muerta en el acto. Según resulta de las averiguaciones hechas por la inspección de vigilancia, a las once de la noche del día 12 se retiraron ambos esposos del paseo, ya la hora arriba mencionada se levantó con el pretexto de que iba a tomar el fresco, arrojándose en seguida a la calle. El señor juez de instrucción procedió al levantamiento del cadáver, y se instruyen las oportunas diligencias ${ }^{52}$.

Así, junto a las ingestas de sustancias venenosas, son los más empleados. Esto no quiere decir que invariablemente obtuvieran éxito en la primera tentativa, pues localizamos reseñas de nuevos intentos de suicidio que ponen de manifiesto la posibilidad real del fracaso. Y, obviamente, un intento de suicidio no alcanza la misma relevancia que uno culminado, alentando la posibilidad real de una infrarrepresentación entre las hojas de los diarios.

SUICIDIO ESPANTOSO. En Marchena se ha suicidado de un modo espantoso, Gracia Barrera Guerrero, mujer del fabricante de harinas D. José Malvar Duarte. Al marchar éste a la fábrica, levantóse de la cama Gracia, y ocultándose de sus hijos se amarró fuertemente a la reja de la ventana por el cuello y por la cintura. Tomó después una botella de petróleo, vertióselo por la cabeza, encendió una cerilla y prendió con ella fuego a las ropas impregnadas de petróleo. Comenzaron a arder los vestidos de la desdichada mujer, y al oir los gritos de ésta, acuden varios vecinos y logran apagar el incendio. Gracia murió achicharrada. Créesela demente. El año pasado se arrojó a un pozo y fue extraída ilesa ${ }^{53}$.

Vemos también un ejemplo de la categorización de la suicida como demente cuando no parece existir una razón objetiva para su proceder. El hecho de que lo intentara hace un año refuerza esa creencia de persona mentalmente inestable, si bien puede ser que se desconozcan los motivos, sean privados, o no hayan salido a la luz. Es algo que tenemos que tener presente en muchas de estas noticias, no siempre se pueden entrever las causas de las acciones y cuando aparecen no siempre son las reales. Ante esto solo podemos citar la fuente y poner en duda la versión oficial cuando parece razonable.

Solamente nos hemos topado con unas líneas que hacían referencia a una mujer con intenciones suicidas que presentara signos claros de su in-

52. La Unión Mercantil, 20/7/1887.

53. La Unión Mercantil, 20/7/1896. 
tención, lo que pudiera hacer plausible tomar medidas para evitarlo, aunque tal prevención no tuvo éxito.

Suicido de una señora. Sevilla 15 -Doña Elisa Márquez, viuda de Lecaroz, salía ayer mañana de su casa, según costumbre, para ir a misa. Como no regresó en todo el día, su familia se alarmó muchísimo. Desde que enviudó hace dos años, se notaba en doña Elisa gran tristeza y poco apego a la vida, padeciendo además constantes neuralgias que hicieron necesario un tratamiento especial facultativo. La familia, viendo que doña Elisa no volvía, sospecha que aquella se había suicidado. Desgraciadamente parece que así ha sido en efecto, porque hoy se ha sabido que una señora, cuyas señas coinciden con las de la viuda de Lecaroz, se arrojó al Guadalquivir al pasar en la barca cerca de Villaverde pereciendo ahogada. Esta desgracia ha producido sensación en Sevilla por tratarse de una señora muy conocida, virtuosa y de arraigadas creencias religiosas ${ }^{54}$.

Tras un duro golpe como es la muerte del marido, el ánimo de la protagonista decayó de tal manera que la gente cercana empezó a sospechar que podría concebir el recurso a una medida desesperada más pronto que tarde. Una vez más una persona conocida que resuelve autodestruirse salta a las páginas de los diarios como muestra de la ruptura de la normalidad. $\mathrm{Si}$ es espinoso discernir los motivos que mueven a una persona a tomar tal determinación, independientemente de los obstáculos que aparecen en cada curso vital, lo es más cuando esta cumple con su papel social y es ferviente creyente; pues como hemos indicado al inicio de este trabajo, la religión se consideraba, incluso por los facultativos, como un bálsamo que calma los dolores del alma y debería impedir actos como el descrito.

\section{CONCLUSIONES}

Esta nueva aproximación a una temática ya abordada desde diferentes ópticas viene a completar y a reforzar la necesidad de aplicar una visión de género dentro de los estudios de Historia.

Como hemos visto a lo largo de estas páginas, las noticias de sucesos certifican la existencia del fenómeno del suicidio femenino, aunque en un menor número que los casos protagonizados por hombres. Las mujeres que acababan con su vida pertenecían a todo el espectro social, desde el 
estrato más bajo hasta el más alto, destacando el gran número adscribible a este último. Sin embargo, no podemos aseverar que este hecho se deba a una mayor concentración de razones que induzcan al suicidio en dicho nivel social, sino que se trata más bien de una información que se juzga relevante, más allá del morbo, debido a que las protagonistas suelen ser personajes destacados y conocidos.

En cuanto a los medios elegidos para quitarse la vida se repite una preferencia por aquellos cercanos y efectivos. Así, el lanzamiento al vacío, a un río o a las vías del tren son los más abundantes. Le sigue la ingesta de sustancias tóxicas (por ejemplo, el ácido clorhídrico), mientras que el resto de opciones son minoritarias.

Por otro lado, el suicidio no resulta cómodo de asimilar, en especial, por la dificultad de entender los motivos que ocasionan tan concluyente trance. En numerosas ocasiones consta el desconocimiento de dichas causas, de las bases profundas que lo originan, pero sorprendentemente hemos localizado múltiples explicaciones en el segmento examinado. El atribuido carácter pasional e irracional de la mujer la enjuicia predispuesta a tomar tales resoluciones cuando entra en juego el desamor. Sin querer rebajar la importancia de la inclinación emocional que pueda concurrir, vislumbramos que la realidad va más allá y, además, se advierte un fuerte sentimiento de frustración y rebelión ante el sistema patriarcal que les indica las normas que han de obedecer y cómo deben comportarse, escudriñando desde su vida pública hasta lo más íntimo, sometiéndolas incluso a reclusión y a limitaciones afectivas y sexuales.

Esta situación se hace más evidente cuando ocurre un episodio de malos tratos. Y de la misma forma se visibiliza en el control que ejerce el padre a la hora de forzar una relación sentimental, la marginación de la madre soltera o el marido que hace de su casa su reino y lo que antes era amor platónico se topa con unas condiciones que reproducen los roles machistas propios de los hogares decimonónicos, independientemente del nivel socioeconómico.

Un repaso de las reseñas estudiadas evidencia una realidad y una enseñanza moral, pues las mujeres que han perdido su vida de tal modo se juzga que han procedido de forma incorrecta. De manera sutil y subliminal, la lectura de dichas referencias muestra el trágico y mortal desenlace de unas mujeres que se "han dejado llevar por sus instintos", que se han rebelado... Por tanto, se transmite el mensaje de que es mejor permanecer sumisa: acatar el dictado de tu cónyuge, padres, hermanos, etc., salvaguardar el honor familiar, y todo ello para poder deambular por la vida según los 
cánones establecidos y reproduciendo el rol preestablecido. Aunque también pueden funcionar como ejemplo de la existencia de otras posibilidades al margen del rumbo establecido.

Cuando todavía no se han descubierto los motivos, se recurre a clasificar a la suicida como una enferma mental, comodín que se emplea asiduamente. La cuestión fundamental, como en todo, es que exista una causa que sea aceptable y que no contenga elementos desestabilizadores para el sistema autoritario decimonónico.

\section{BIBLIOGRAFÍA}

Albert, Pierr; Guash, Juan María y SÁnchez Aranda, José Javier (1990), Historia de la prensa, Rialp, Madrid.

Álvarez, Jesús Timoteo (1981), Restauración y prensa de masas: los engranajes de un sistema (1875-1883), Universidad de Navarra, Pamplona.

Amador Rivera, Gonzalo H. (2015), "Suicidio: consideraciones históricas", Revista Médica La Paz, 21 (2), pp. 91-98.

Awad, Gloria (1995), Du sensationnel: place de l'événementiel dans le journalisme de masse, Editions L'Harmattan, París.

De Miguel, Jesús Manuel (1970), "El suicidio en España”, Revista Internacional de Sociología, 28, 109, pp. 21-44.

DiÉguez, Antonio (2010), "Perspectivas sobre las pasiones en la España del período romántico", Frenia. Revista de Historia de la Psiquiatría, X, pp. 29-48.

Durkheim, Émile (1999), El suicidio, Akal, Madrid.

Fernández Labbé, Marcos (2006), "Incapaz de soportar ya esta vida. Suicidio femenino en Chile. 1884-1948", Nuevo Mundo Mundos Nuevos. URL: <http:// dx.doi.org/10.4000/nuevomundo.2850> (Consulta: 20/8/2019).

Gómez de Rueda, Isabel Gómez (1997), "Ritos exequiales. No creyentes, no bautizados y suicidas", Revista Murciana de Antropología, 2, pp. 179-187.

Llamas Pont, Manuel (1996), "Una monografía inédita de Gaziel sobre la premsa espanyola: context, comentari i edició", Anàlisi. Quaderns de comunicació $i$ cultura, 19, pp. 11-54.

Lezcano, Víctor Morales (1979), "Revista España, semanario de la vida nacional (1915-1924)”, Hispania. Revista Española de Historia, XXXIX, 141, pp. 201-220.

Martínez Pérez, José (2001), "Suicidio, crisis política y medicina mental en la Francia del siglo XIX (1801-1885)", Frenia. Revista de Historia de la Psiquiatría, I, 2, pp. 39-65.

Miralles, Fernando y Cano, Antonio (2009), "Suicidios en soldados de las Fuerzas Armadas de España en la última década del Servicio Militar Obligatorio (1991-2001), Clínica y Salud, 20, 2, pp. 189-196. 


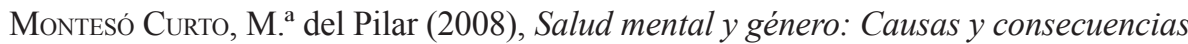
de la depresión en las mujeres. Tesis doctoral defendida en el Departamento de Sociología III, Facultad de Ciencias Políticas y Sociología, de la UNED. URL: <http:/espacio.uned.es/fez/eserv/tesisuned:CiencPolSocMpmonteso/ Documento.pdf> (Consulta: 12/8/2019).

Moreno SÀrda, Amparo (2006). "Comprender la globalidad desde la proximidad: Aportaciones no-androcéntricas a la construcción de un humanismo plural", F@ro. Revista teórica del Departamento de Ciencias de la Comunicación, 4. URL: <https://dialnet.unirioja.es/descarga/articulo/2225729.pdf> (Consulta: 26/8/2019).

- (2007), De qué hablamos y no hablamos cuando hablamos del hombre: treinta años de crítica y alternativas al pensamiento androcéntrico, Icaria, Barcelona.

Ortega Muñoz, Víctor J. (2012), Conflictividad social e información de sucesos en la Restauración. Tesis doctoral defendida en el Departamento de Historia Moderna y Contemporánea de la Universidad de Málaga. URL: <https:// riuma.uma.es/xmlui/bitstream/handle/10630/5383/TDR_ORTEGA_MUNIOZ. pdf? sequence $=1 \&$ is Allowed $=y>($ Consulta: $16 / 8 / 2019)$.

- (2016a), "Honor, venganza y construcción social del delito en la prensa de la Restauración”, Clío \& Crimen, 13, pp. 269-288.

- (2016b), "Control social, locura y noticias de sucesos durante la Restauración", en S. Núñez de Prado Clavell, P. M. a de la Fuente Polo, M. Perruca Gracia y J. Rodríguez Abengózar (eds.), I Congreso de Jóvenes Historiadores: Actas, Universidad Rey Juan Carlos, Madrid, pp. 559-576.

- (2018), iExtra, Extra! Poder, información y control de la sociedad española en las noticias de sucesos, 1881-1923, Pórtico, Zaragoza.

PAlacio, Andrés Felipe (2010), "La comprensión clásica del suicidio. De Emile Durkheim a nuestros días", Affectio Societatis, 7, 12, pp. 1-12.

Pizarroso Quintero, Alejandro (1994), "Evolución histórica de la prensa en España”, en A. Pizarroso Quintero (coord.), Historia de la prensa, Centro de Estudios Ramón Areces, Madrid.

Plumed Domingo, José Javier y Novella, Enric J. (2015), "Suicidio y crítica cultural en la medicina española del siglo XIX”, Dynamis, 35 (1), pp. 57-81.

Plumed Domingo, José Javier y Rojo Moreno, Luis (2012), "La medicalización del suicidio en la España del siglo XIX: aspectos teóricos, profesionales y culturales", Asclepio, LXIV, 1, pp. 147-166.

Rodríguez Magda, Rosa María (1994), Femenino fin de siglo. La seducción de la diferencia, Anthropos, Barcelona.

Seonne, María Cruz y SÁiz, M. ${ }^{a}$ Dolores (1998), Historia del periodismo en España. 3. El siglo XX: 1898-1936, Alianza, Madrid.

Seonne, María Cruz (1977), Oratoria y periodismo en la España del siglo XIX, Castalia/Fundación March, Valencia.

Tuñón de LARA, Manuel (1973), Metodología social de España, Siglo XXI, Madrid. 
Velasco Salles, María del Mar y Pujal i Llombarte, Margot (2005), “Reflexiones en torno al suicidio: desestabilizando una construcción discursiva reduccionista”, Atenea Digital. Revista de Pensamiento e Investigación Social, 7, pp. 133-147. URL: https://doi.org/10.5565/rev/athenead/v1n7.186 (Consulta: 15/8/2019). 